\title{
W and Mo Thin Films Electrodeposited from Aqueous Solutions
}

\author{
M. Saitou \\ University of the Ryukyus, Department of Mechanical Systems Engineering, 1 Senbaru Nishihara-cho \\ Okinawa, 903-0213, Japan. \\ E-mail: saitou@tec.u-ryukyu.ac.jp
}

doi: $10.20964 / 2021.01 .14$

Received: 5 September 2020 / Accepted: 29 October 2020 / Published: 30 November 2020

Thin films electrodeposited from aqueous solutions containing W(VI) or Mo(VI) ions using rectangular pulse voltages with a $1 \mathrm{MHz}$ frequency were investigated using scanning electron microscopy-energy dispersive X-ray (SEM-EDX) spectroscopy and X-ray diffraction (XRD). SEM-EDX analyses confirmed that the obtained thin films comprise $\mathrm{W}$ or Mo. The current efficiency increased with the cathode potential and tended to become constant, which is consistent with the phenomenological theory of electrodeposition. The potential barrier of $\mathrm{W}^{6+}$ and $\mathrm{Mo}^{6+}$ was $6.5 \mathrm{~V}$ and the maximum current efficiency (achieved by the $\mathrm{W}$ thin film) was $2.3 \%$. XRD analyses revealed that the $\mathrm{W}$ and Mo thin films have a body-centered cubic and amorphous structure, respectively.

Keywords: W and Mo thin films; Aqueous solution; Phenomenological theory; Body-centered cubic; Amorphous

\section{$\underline{\text { FULL TEXT }}$}

(C) 2021 The Authors. Published by ESG (www.electrochemsci.org). This article is an open access article distributed under the terms and conditions of the Creative Commons Attribution license (http://creativecommons.org/licenses/by/4.0/). 